Cinémas

Revue d'études cinématographiques

Journal of Film Studies

\title{
Figuration du personnage : l'Indien du cinéma américain
}

\section{Martin Lefebvre}

Volume 1, numéro 1-2, automne 1990

Américanité et cinéma

URI : https://id.erudit.org/iderudit/1000990ar

DOI : https://doi.org/10.7202/1000990ar

Aller au sommaire du numéro

Éditeur(s)

Cinémas

ISSN

1181-6945 (imprimé)

1705-6500 (numérique)

Découvrir la revue

Citer cet article

Lefebvre, M. (1990). Figuration du personnage : l'Indien du cinéma américain. Cinémas, 1(1-2), 44-59. https://doi.org/10.7202/1000990ar

\section{Résumé de l'article}

L'américanité est abordée au moyen d'une vision intérieure à l'Amérique elle-même, telle que définie par son auto-représentation dans un corpus filmique bien précis, le film d'Indien, et par son traitement d'une altérité qui l'habite, celle de l'indianité. L'analyse se fait à travers un film, le célèbre One Flew Over the Cuckoo's Nest de Milos Forman. L'étude des éléments déterminants pour l'identification de la catégorie de personnage démontre que si le film n'est pas un western, l'utilisation du modèle du western et du réseau normatif qu'on peut en abstraire permet de déceler des liens structuraux indéniables quant à la représentation de l'Indien. 


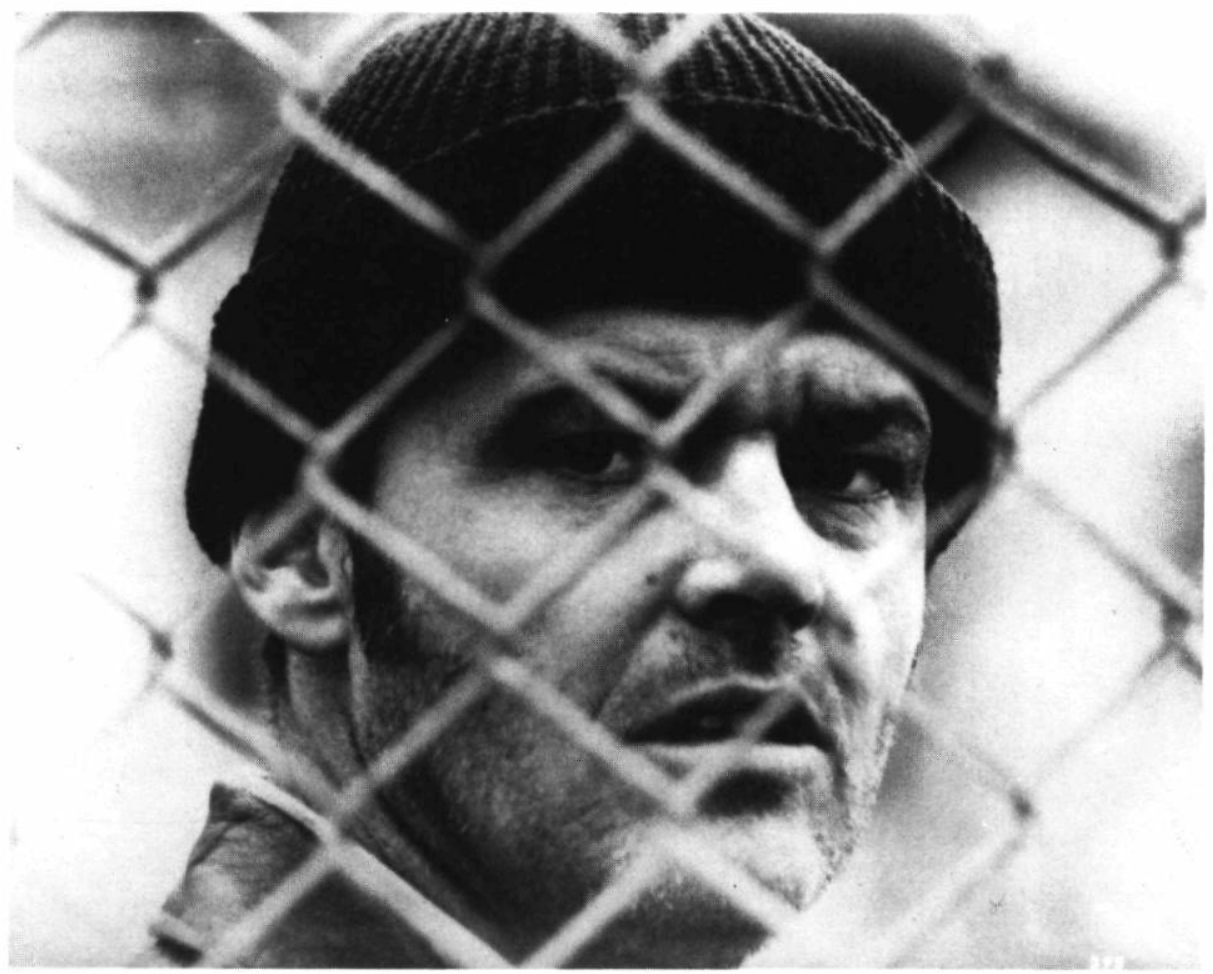

One Flew Over the Cuckoo's Nest de Milos Forman (1975) Coll. Cinémathèque québécoise 


\title{
Figuration du personnage: l'Indien du cinéma américain
}

\section{Martin Lefebvre}

\begin{abstract}
RÉSUMÉ
L'américanité est abordée au moyen d'une vision intérieure à l'Amérique elle-même, telle que définie par son auto-représentation dans un corpus filmique bien précis, le film d'Indien, et par son traitement d'une altérité qui l'habite, celle de l'indianité. L'analyse se fait à travers un film, le célèbre One Flew Over the Cuckoo's Nest de Milos Forman. L'étude des éléments déterminants pour l'identification de la catégorie de personnage démontre que si le film n'est pas un western, l'utilisation du modèle du western et du réseau normatif qu'on peut en abstraire permet de déceler des liens structuraux indéniables quant à la représentation de l'Indien.
\end{abstract}

\begin{abstract}
Américanité, "Americanness", is approached in terms of a way of seeing internal to America itself, as exemplified in a well-defined corpus of film, the Indian film and the treatment of "Indianness" as a form of otherness that informs it. The analysis is based on one film, Milos Forman's famous One Flew Over the Cuckoo's Nest. A study of the elements which determine the identification of this character category reveals that though this film is not a Western, the use of the Western model and of the normative network that can be abstracted from it exhibits undeniable structural links in the way it represents the Indian.
\end{abstract}

Si la notion d'américanité risque de renvoyer presque nécessairement à une pratique de croisements culturels et à une certaine vision du dehors, tel que souligné jadis par Roland Barthes ${ }^{1}$, c'est 
dans une optique différente, celle d'une vision de l'intérieur, que je vais essayer ici de dégager une des figures de proue de cette notion. Contrairement à Barthes, pour qui le suffixe «ité» servait à examiner le déplacement d'unités discrètes dans une pratique d'altérité constitutive du sens (par ex.: la romanité des films hollywoodiens ou l'italianité des publicités françaises, etc.) et impliquait en cela une dualité de points de vue, je propose plutôt un retournement qui fait de l'américanité non pas une vision extérieure du propre américain (vision qu'en aurait le Québec, la France, l'URSS, etc.), mais une vision intérieure à l'Amérique elle-même, telle que définie par son auto-représentation dans un corpus filmique bien précis, le film d'Indien, et par son traitement d'une altérité qui l'habite, celle de l'indianité.

C'est donc en raison de l'expression cinématographique des premiers Américains, qui sont justement désignés par le terme de Native Americans aux États-Unis, que je tente de cerner le travail d'une lecture constitutive de ce système symbolique, ou idéologie qu'on nomme ici américanité. Pour ce faire, j'identifie certains éléments déterminants de la catégorie personnage au sein de ce système symbolique. En cela, mon approche n'est pas une sémiologie du personnage au sens où l'entend $\mathrm{P}$. Hamon ${ }^{2}$, ni une étude qui examinerait les fondements de la catégorie personnage comme un préconstruit à la lecture des films de fiction ${ }^{3}$. Bien qu'elle reconnaisse la nécessité de telles approches en les présupposant, mon analyse se situe plus volontiers en aval, c'est-à-dire qu'elle examine plutôt l'au-delà que l'en deçà du récit.

Le film analysé est le célèbre One Flew Over the Cuckoo's Nest de Milos Forman. Les raisons de ce choix sont multiples: ce film est bien connu, il a été apprécié par le public et par la critique, de même que par l'institution cinématographique américaine qui lui a décerné l'Oscar du meilleur film en 1975. De plus, à sa sortie, plusieurs Amérindiens ou membres de groupes pro-amérindiens se sont dits satisfaits de la représentation du chef Bromden. Gretchen M. Bataille et Charles L. P. Silet, par exemple, voient avec ce film l'espoir d'un changement dans la représentation de l'Indien au cinéma. Ils écrivent, dans The Pretend Indians: "The most recent hope for a change in the portrayal [of Native Americans] may be with such films as One Flew Over the Cuckoo's Nest in which Bromden's Indianness, although significant symbolically, is somewhat accidental" (p. 133).

J'avoue que c'est cette reconnaissance unanime provenant à la fois de l'institution cinématographique américaine et des groupes pro-amérindiens qui a d'abord soulevé ma curiosité: elle rassemble après tout des points de vue traditionnellement opposés. En effet, si le cinéma hollywoodien s'est constitué à partir de toutes sortes de 
contradictions qui vont de la glorification de l'individualisme à l'éloge de l'intégration sociale, les quelques films ayant ouvertement promu la marge ont rarement joui du support incontesté de l'institution cinématographique américaine. C'est donc de cette apparente contradiction dont il sera question ici.

\section{One Flew Over... the Western}

Le livre du même titre, écrit par l'américain Ken Kesey, a déjà été étiqueté comme un western par l'essayiste Leslie Fiedler ${ }^{4}$. En fait, selon ce dernier, tout récit mettant en scène un ou des Indiens est avant tout un western. À première vue, cette thèse ne s'accorde guère avec le film de Forman qui se déroule au $\mathrm{XX}^{\mathrm{e}}$ siècle, dans les années 60, soit bien après la conquête de l'Ouest américain ${ }^{5}$. Qu'en est-il cependant si on interroge le film au moyen du western, si on traduit le film sur l'espace conflictuel du western?

On ne peut douter de l'importance de la place du western dans la représentation de l'Indien au sein du cinéma américain. L'image de l'Indien appartient aux conventions du genre, à tel point que Jean-Louis Leutrat remarque «que la langue populaire, lorsqu'elle veut désigner par une périphrase un Western, dit tantôt film de cow-boys, tantôt film d'Indiens» (p. 95). Mais si le rapport Indien/western est facilement reconnaissable, il n'est pas simple. J'ai montré ailleurs comment il est nécessaire de distinguer les personnages indiens de l'indianité, qui constitue une série de traits sémantiques et iconographiques mobiles généralement propre à l'Indien, mais pouvant se déposer sur d'autres personnages ${ }^{6}$. Cette distinction explique pourquoi on ne retrouve pas des protagonistes indiens dans tous les westerns, bien qu'ils s'y retrouvent majoritairement. La distinction Indien/indianité apparaît aussitôt qu'on considère le rôle structural de l'Indien dans l'espace conflictuel du western.

Depuis quelques années, bon nombre d'études ont montré comment le western se construit sur une tension générée par l'opposition dialectique de la culture et de la nature. En ce sens, si le cadre historique - généralement entre 1860 et 1890 - rend vraisemblable la présentation massive de personnages indiens dans des films illustrant souvent les efforts colonisateurs de la conquête de l'Ouest américain, c'est surtout en vertu de cette opposition, sur laquelle repose le genre tout entier, que la présence de personnages indiens se justifie dans ces films. Selon cette perspective, la conquête de l'Ouest américain correspond à l'imposition de la civilisation sur une contrée jusqu'alors sauvage. Les théoriciens du genre (John Calweti ${ }^{7}$; Thomas Schatz ${ }^{8}$; Will Wright ${ }^{9}$; Jim Kitses ${ }^{10}$ ) conçoivent généralement cette dialectique selon deux paradigmes antinomiques, celui de la sauvagerie et celui de la civilisation, à l'intérieur desquels ils inscrivent toutes les conventions du genre. 
Vue sous cet angle, l'utilisation de personnages indiens signifie beaucoup plus que le simple respect d'une reconstitution historique. Une fois inscrit dans ce paradigme, l'Indien devient un des principaux représentants de la nature et de la sauvagerie. Il est un être dont le concept se justifie par la structure même de l'univers western, et non plus par la simple situation historico-géographique des films. L'Indien incarne alors littéralement l'arrière-plan contre lequel il est généralement filmé, la plaine et les steppes, et devient la personnification même du concept de nature. En fait, l'Indien, le personnage, s'évanouit au profit d'une indianité réduite strictement à un état de nature.

La simplicité de ce rôle invite à voir pourquoi certains westerns peuvent aisément se passer de protagonistes indiens. L'indianité, parce que hautement conventionnalisée, peut être transmise à d'autres protagonistes et, le cas échéant, les personnages indiens perdent, à toutes fins pratiques, leur utilité narrative. Le hors-laloi, par exemple, peut offrir toutes les caractéristiques d'un homme ensauvagé et s'indianiser. Ce qui importe surtout, c'est la re-création du conflit entre la nature et la culture, et non l'Indien en tant que tel.

Si ce conflit est l'élément de base de la construction de l'univers du western, il est réducteur de vouloir limiter celui-ci à la simple opposition entre la sauvagerie et la civilisation. À elle seule, cette opposition est incapable de rendre compte de la dynamique réelle du genre. En termes d'espaces, l'opposition de base du western met en rapport l'Est et l'Ouest, espaces respectifs de la civilisation et de la sauvagerie. Il faut voir cependant que ce rapport antinomique permet la création d'un nouvel espace servant de médiation entre l'Ouest et l'Est, entre la nature et la culture. Cet espace, c'est la frontière. Elle s'intègre dans la structure de l'univers du western comme un troisième terme complétant l'opposition dialectique. Il est important de saisir la spécificité du western dans l'articulation de ces trois termes. Le western n'est pas le seul type de récit à poser l'opposition nature/culture, il la pose toutefois à un moment précis de l'histoire américaine où le conflit entre ces deux pôles n'est pas encore résorbé. En effet la majorité des westerns, en situant l'action dans la période entre 1860 et 1890 , montre cette opposition au plus fort de la crise. Le western, par ses thèmes, tend à illustrer le conflit à son point culminant, soit à une époque où chaque côté peut encore gagner.

Lieu de confrontation entre la nature et la culture, la frontière n'appartient ni à l'Ouest ni à l'Est, ni à la nature ni à la culture, et bien que sa progression à l'intérieur du territoire américain soit un fait de civilisation, elle appartient aux deux. 
Comme progression géographique, la frontière représente les limites successives du développement de la civilisation. Comme emplacement, elle agit plutôt comme un véritable no man's land, le lieu d'une altérité conflictuelle. Les habitants de la zone frontalière ne sont des habitants ni de l'Est ni de l'Ouest. Ils ne sont ni Yankees, ni Indiens. En cela, la frontière forme un espace distinct de l'Est et de l'Ouest.

Nous pouvons représenter cet univers à l'aide du schéma suivant:

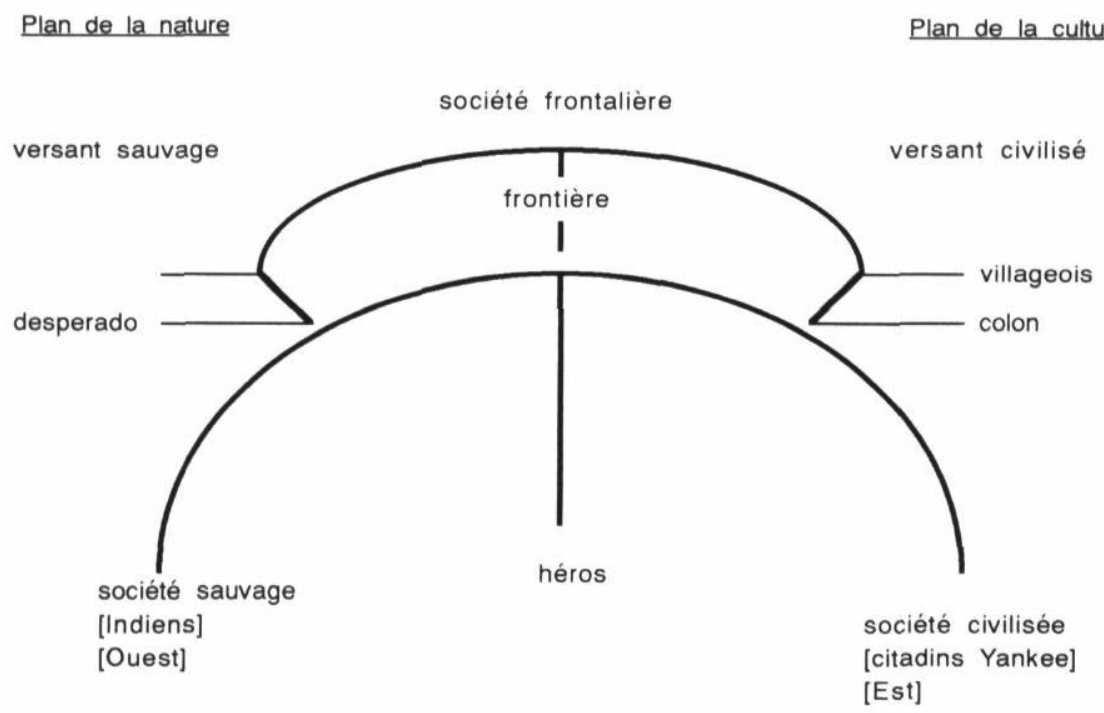

Fig. 1

Structure de l'univers du western.

Ce schéma montre la structure et le fonctionnement de l'univers du western. On retrouve, aux deux extrémités du spectre, les termes de l'opposition entre la nature et la culture. Ces deux termes ont la même valeur structurale: ils servent tous deux à créer leur propre cadre de référence narratif, soit respectivement une société sauvage et une société civilisée. Ces deux sociétés sont représentées par des protagonistes indiens pour l'une et des protagonistes citadins pour l'autre. On retrouve là évidemment l'opposition Est/Ouest, établie sur l'axe géographique horizontal de la conquête du territoire américain. Au centre, c'est la frontière, servant de médiation entre les deux espaces de l'Ouest et de l'Est. Il s'agit d'un espace imaginaire, de l'espace discursif du western, là où la tension générée par l'opposition de base se transforme en véritable conflit: espace imaginaire par son déplacement constant entre 1860 et 1890 qui l'empêche de se cristalliser en un espace 
réel complet, mais aussi parce qu'il s'agit du lieu de conflit entre la nature et la culture; espace discursif car c'est là, avant tout, que l'action du western se déroule.

La frontière forme un lieu hétéroclite. On y retrouve tant des éléments qui appartiennent à la nature (cow-boys ensauvagés ou desperados), que des éléments qui appartiennent à la culture (colons, villageois, commerçants). Cette société reproduit en microcosme les éléments de l'opposition de base; toutefois son hétérogénéité définit une société distincte des deux autres qui sont bien homogènes. Cette mixture d'éléments forme en fait un nœud, un ensemble de contradictions qui vont se déposer sur le héros, seul véritable habitant de la frontière. Le héros représente thématiquement et narrativement toutes les contradictions de la société frontalière. Il est une sorte de métis: un être à la fois sauvage et civilisé. C'est de ce métissage qu'il tire les qualités qui font de lui un être supérieur, même s'il s'agit d'une supériorité souvent très éphémère. Car le héros suit un programme narratif qui l'amène inévitablement à résorber ses contradictions et à s'inscrire définitivement dans un des deux pôles de base, ce qui lui fait perdre sa supériorité. Le travail ultime du film western apparaît alors comme la destruction de la frontière; le héros travaille constamment à sa propre perte: le centre dans lequel il se déplace et oscille doit être détruit afin que se règle le conflit initial.

Le western, en définitive, met en scène trois grand types de personnages tributaires des trois espaces qu'ils représentent. On retrouve le sauvage, le frontalier et le civilisé, et qui sont respectivement l'Indien, le héros et le citadin. Tous sont illustrés à l'écran par des traits sémantiques et iconographiques spécifiques. L'Indien, par exemple, est reconnu à son costume, mais aussi à son physique souvent imposant et bien proportionné, ses longs cheveux, son caractère taciturne et son usage de l'arme blanche. Il peut être belliqueux et mauvais ou sage et bon. Tous ces traits se joignent à la contiguïté spatiale de l'Indien et du territoire sauvage et servent à constituer l'indianité en liant l'Indien à la nature. Menaçant comme un fauve ou doux comme un agneau, brute féroce ou bon sauvage, l'Indien du western est foncièrement toujours le même. Ses différentes figurations filmiques ne sont jamais que des variations sur un même thème, celui de la correspondance entre l'Indien et la nature. Mais au-delà des simples variations entre bons et méchants Indiens, il importe de voir quel réseau normatif (c'est-à-dire quelle formulation idéologique de l'américanité dans le cinéma américain) rend possible de telles valorisations. C'est le rapport final du héros à la frontière qui permet la mise en jeu des différentes valeurs que le western accorde à l'Indien. En effet, l'hypothèse que j'ai déjà éprouvée ailleurs montre comment 
l'Indien du western sera bon ou mauvais selon que le héros se situe dans un ou l'autre des versants de la frontière ${ }^{11}$. Celle-ci agit alors comme un véritable baromètre discursif: c'est l'oscillation du héros vers l'un ou l'autre versant de la frontière qui établira la valeur que le film confère à l'Indien.

À partir des distinctions amenées par Will Wright pour décrire l'évolution du genre depuis le parlant, ce modèle a été opératoire pour montrer que l'Indien subit une valorisation négative dans le western classique et sa variation, le western de vengeance - films où le héros finit par s'intégrer au sein du versant civilisé de la société frontalière (Stagecoach, Shane, My Darling Clementine). En revanche, j'ai montré comment l'Indien est valorisé positivement lorsque le héros n'intègre pas le versant civilisé, comme c'est le cas pour le western de transition (Broken Arrow) et le western professionnel - où toutefois il n'apparaît pratiquement pas puisqu'il est remplacé par un (ou des) héros ensauvagé(s) qui reproduise(nt) l'opposition de base (The Wild Bunch). En d'autres termes, aux déplacements vers la civilisation correspond une représentation négative de l'Indien, tandis qu'aux déplacements du héros vers la sauvagerie correspond une valorisation positive de l'Indien. Le western sert à montrer comment le rôle de l'Indien est subordonné à une indianité qui se constitue selon un principe de contiguïté avec le territoire sauvage de l'Ouest américain. Dans le western, seul le héros peut franchir la ligne frontalière qui sépare les deux plans de cet univers. L'Indien est prisonnier de son lien avec la nature et ne peut se déplacer. Le but de son indianité est de mettre en place et d'activer un système d'oppositions sur lequel se construit le discours western.

\section{One Flew Over The Cuckoo's Nest}

Faisant déborder l'intuition de Fiedler sur le film de Forman, il est possible d'intégrer celui-ci dans le réseau symbolique fortement constitué du western, et d'examiner le rapport personnage/territoire, tout en prenant bien soin de distinguer entre l'Indien et l'indianité.

Cela m'autorise à retrouver, et ce dès l'ouverture du film, une opposition nature/culture qui reproduit le modèle oppositionnel de base du western. En effet, vus sous cet angle, les deux premiers plans du film révèlent sans équivoque l'enjeu. Le film s'ouvre sur un plan général qui montre une partie encore sauvage de la contrée américaine: il s'agit d'une montagne qui occupe le centre du cadre. Le plan est fixe et accompagné d'une musique à fortes connotations indiennes (tam-tam, tambourine, etc.). Lorsqu'une voiture apparaît au bas de l'image, on découvre que la montagne est derrière une route qui nous était plus ou moins cachée (suite à l'arrivée de McMurphy quelques plans plus tard, il est possible d'inférer que 
c'est la voiture qui le transporte). Une coupe franche nous introduit ensuite à l'intérieur de l'institut psychiatrique. Le simple montage des deux plans suffit pour instaurer les balises de l'opposition nature/culture qui va se développer tout au long du film. Ce rapport, cependant, se construit sur l'absence de la frontière historico-géographique du western et ne répond pas de façon rigoureuse à l'organisation interne de ce genre. Notons à cet effet l'absence d'éléments conventionnels indicatifs de la structure ternaire du western (costumes, moyens de locomotion, armes, etc.). On se retrouve en premier lieu devant un système régi par une simple opposition binaire: d'une part la montagne, qui semble intouchée d'abord, mais dont l'équilibre est sérieusement menacé par la présence de l'homme civilisé (route, voiture); d'autre part, l'institut psychiatrique, apogée de la culture, haut lieu de la science, où tout est blanc, aseptisé. C'est l'ordre le plus total, assuré par une infirmière pratiquement asexuée. Le film se déroule près d'un siècle après la destruction de la frontière séparant l'Est de l'Ouest américain, à un moment où le rapport de forces du conflit initial est déjà réglé. Cela a pour effet de polariser la répartition des rôles. En ce sens, il est clair que le film n'est pas un western au sens strict. L'arrivée de McMurphy, héros du film, permettra cependant de redéployer cet espace post-western en une nouvelle triade. En effet, le statut de héros de ce personnage dépend de la création d'un nouvel espace frontalier, que l'hôpital occupera structuralement. On peut d'ailleurs schématiser de la même façon l'axe oppositionnel du film:

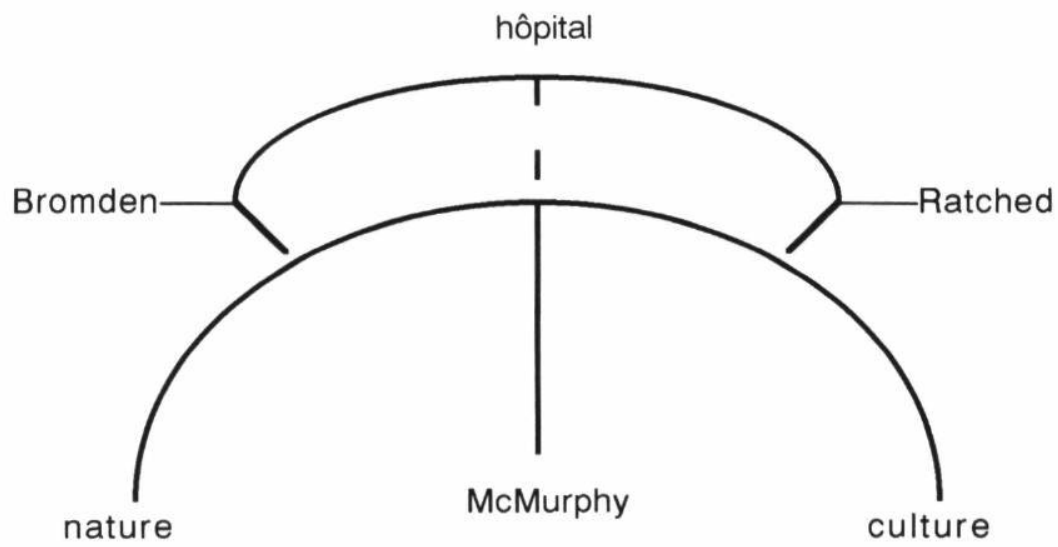

Fig. 2

Schéma de l'univers du western appliqué à One Flew Over the Cuckoo's Nest. 
Tout comme la frontière de l'univers du western, l'hôpital constitue ici un espace bifide. D'une part, il représente le développement de la civilisation et on y retrouve des docteurs, des infirmiers et infirmières, des gardes de sécurité, tous des représentants de la culture. D'autre part, on y retrouve des fous. Ceux-ci sont de deux types: des résidents externes qui vivent à l'hôpital mais qui ne sont pas tenus d'y rester (Martini, Cheswick, Billy, etc.) et des malades qui sont ni plus ni moins prisonniers, dont Bromden et McMurphy. Pour les externes, l'hôpital représente un lieu de passage permettant de réintégrer la société, pour les autres, il représente une sorte de Narrenschiff qui vise l'exclusion, la ségrégation des marginaux ${ }^{12}$. Il n'est pas surprenant de retrouver ces fous dans le plan de la nature, avec Bromden et McMurphy. En effet, depuis l'histoire biblique de Nabuchodonosor jusqu'à sa représentation par William Blake au XVIII' siècle $^{13}$, en passant par les illustrations médicales de Charles Bell14, une étroite corrélation existe entre les représentations de la folie et de la sauvagerie. Comme l'indique d'ailleurs Roland Jaccard:

La folie jouit d'un certain prestige culturel; elle promet, croit-on, un univers primordial, une existence sauvage, ouvrant un horizon infini d'expériences. Dans la nuit de la raison, l'homme est supposé communiquer avec les forces génératrices que la nature refuse à l'entendement 15 .

Folie et sauvagerie participent ainsi à une iconographie et à une thématique qui se recoupent.

En ce qui a trait à cette nouvelle frontière entre la nature et la culture, elle n'est plus l'emplacement d'un conflit encore existant. Le conflit original étant bien réglé, l'échelle de cette frontière est réduite. L'hôpital devient un lieu symbolique où s'anime un conflit local et clos qui reprend les termes de l'opposition du western. C'est pourquoi à la fin du film, avec le départ de Bromden et la mort de McMurphy, la structure frontalière disparaît au profit d'un univers binaire qui, comme au début du film, polarise l'opposition nature/culture. Avec la mort du héros frontalier et le départ de Bromden vers la montagne, l'hôpital perd son statut de frontière: il ne représente maintenant qu'un lieu de civilisation, comme toute autre construction de la culture.

En tant que héros, McMurphy occupe cette frontière qui se déploie dès son arrivée à l'hôpital. Sa participation aux discussions de groupe avec les patients externes et Miss Ratched le démarque des autres malades. Les docteurs sont incertains quant à sa véritable situation mentale. Mais comme le héros du western professionnel, il devient pratiquement impossible pour lui de franchir la frontière. Aussi l'informe-t-on que sa libération n'aura lieu qu'à partir du moment où les autorités médicales le décideront. Cepen- 
dant, l'appartenance définitive de McMurphy et de Bromden au plan de la nature ne tient pas qu'à leur statut de prisonniers dans l'institut psychiatrique.

\section{Indien et indianité}

Grâce au modèle de l'univers du film (fig. 2), nous sommes en mesure d'examiner la valorisation et la représentation des personnages. Si le film anime l'opposition nature/culture, il met aussi en scène un Indien. En fait on en retrouve plutôt deux.

D'abord Bromden, l'Indien de race. Un des changements les plus importants de l'adaptation du roman de Kesey est l'omission de la narration à la première personne par le chef Bromden au profit d'une narration omnisciente. Si cela implique que le spectateur éprouve le même effet de surprise que McMurphy lorsqu'il découvre que l'Indien peut parler et même penser, Bromden, lui, se voit devenir doublement muet. Non seulement il perd la responsabilité du récit des événements, mais il passe de surcroît près de la moitié du film dans le plus grand silence. Le film enlève littéralement la parole à l'Indien. Il faut dire d'ailleurs que celui-ci n'a jamais beaucoup parlé dans le cinéma américain et le mutisme du chef Bromden ne fait qu'ajouter un exemple de plus au stéréotype de l'Indien taciturne.

Bromden est aussi caractérisé par ses cheveux longs, son physique imposant, et la «sagesse» dont il fait preuve en demeurant muet (McMurphy, exalté, lui dit: "You fooled them all" [Tu les as tous bien eus]). Puis, avant de s'évader, Bromden dit se sentir «gros comme une montagne»: c'est celle du premier plan, sans doute, vers laquelle il court à la fin, au son de la musique qui ouvrait le film. L'histoire de Bromden, sa transformation, suggère la résurrection d'une force de la nature - force avec laquelle il soulève l'appareil d'hydrothérapie et l'envoie par la fenêtre pour s'évader de l'institut.

Mais comme je l'ai souligné plus haut, Bromden n'est pas le seul Indien du film. En fait, de façon structurale, McMurphy est plus indianisé que le chef. Avant l'arrivée de McMurphy, Bromden ne peut servir d'opposition à la culture. C'est-à-dire qu'il ne peut pas remplir le rôle structural que le western lui a confié. Il est assimilé, aliéné par la civilisation. Il n'est qu'une autre caricature de l'Indien, un autre tonto (c'est-à-dire fou en espagnol). C'est l'arrivée de McMurphy qui va permettre de constituer une véritable opposition à l'ordre établi par la culture.

McMurphy, dont le nom porte encore le stigmate des vieux pays, est vraisemblablement le descendant du héros western qui, après l'effritement de la frontière, occupait l'espace de la nature. Il est étroitement lié à celle-ci: la voiture qui l'amène passe par la mon- 
tagne et la musique qui signale son arrivée indique aussi la libération de Bromden/nature à la fin du film.

C'est en tant que représentant de la nature que McMurphy s'oppose à l'infirmière Ratched. Si McMurphy est identifié à l'espace de la nature par un principe de contiguïté qui le rattache à la montagne, comme beaucoup d'Indiens ou comme certains héros ensauvagés du western, l'infirmière Ratched est également liée à l'espace de la culture: on ne la voit jamais à l'extérieur de l'hôpital. Cette opposition est d'ailleurs soulignée visuellement lorsque les deux antagonistes sont introduits pour la première fois. Tels deux boxeurs pénétrant dans l'arène, leur entrée à l'hôpital est présentée pratiquement de la même façon. Dans les deux cas, les personnages sont pris par une caméra fixe et cadrés au centre de l'image par un plan moyen qui passe à un plan américain à mesure qu'ils avancent vers la caméra. L'analogie formelle de la présentation nous aide à percevoir sous l'angle d'une relation oppositionnelle les différences de comportement entre les deux personnages. À l'égard de la situation développée par la suite, la désinvolture de McMurphy répond au stoïcisme et à la rigidité de Miss Ratched. Cette désinvolture prend sans équivoque la direction de l'indianité un peu plus loin dans la même séquence lorsque McMurphy, faisant le pitre aux dépens de Bromden, crie et danse à l'indienne.

Mais l'indianité de McMurphy est aussi représentée par ses traits et ses actions. Il est caractérisé par son tempérament belliqueux (il se battait souvent en prison), il est sale (sa tenue est toujours plus négligée que celle des autres), ivrogne, paresseux et irrespectueux de la loi. Sa vie entière s'est déroulée sous le signe de la violence et de la sexualité16 (il est en prison pour le viol d'une mineure) et la société - le corps médical - le considère comme dangereux. N'est-ce pas là un ensemble de traits négatifs qui sont généralement attribués aux Indiens dans les westerns de type classique?

McMurphy est donc doublement indianisé: par le rôle structural qu'il joue en s'opposant à l'infirmière Ratched et par une série de traits caractéristiques de la représentation des Indiens au cinéma. Et pour tous ceux qui auraient manqué la référence, une scène est insérée où Bromden lui-même explique à McMurphy comment il lui rappelle son père, un véritable chef indien: grand, fort, fier et courageux.

Enfin, McMurphy, à l'instar du héros du western professionnel, n'intègre pas le plan de la culture. Le film retrace la transformation du personnage de l'Indien en examinant le transfert et l'acquisition de traits mobiles qui permettent son indianisation. C'est McMurphy, ce faux Indien, qui redonne à Bromden son rôle traditionnel et le replace sur l'échelle dialectique de l'opposition nature/culture. La mort de McMurphy est ainsi sacrificielle: ayant 
redonné au chef son indianité, McMurphy n'a à proprement parler plus de rôle à jouer. Suivant ainsi la même logique narrative qui écarte les personnages indiens des westerns professionnels, McMurphy, dès qu'il permet au chef de retrouver son indianité, est évacué de l'argument narratif. On peut représenter les déplacements à l'aide de ces schémas qui reproduisent le système oppositionnel du film:

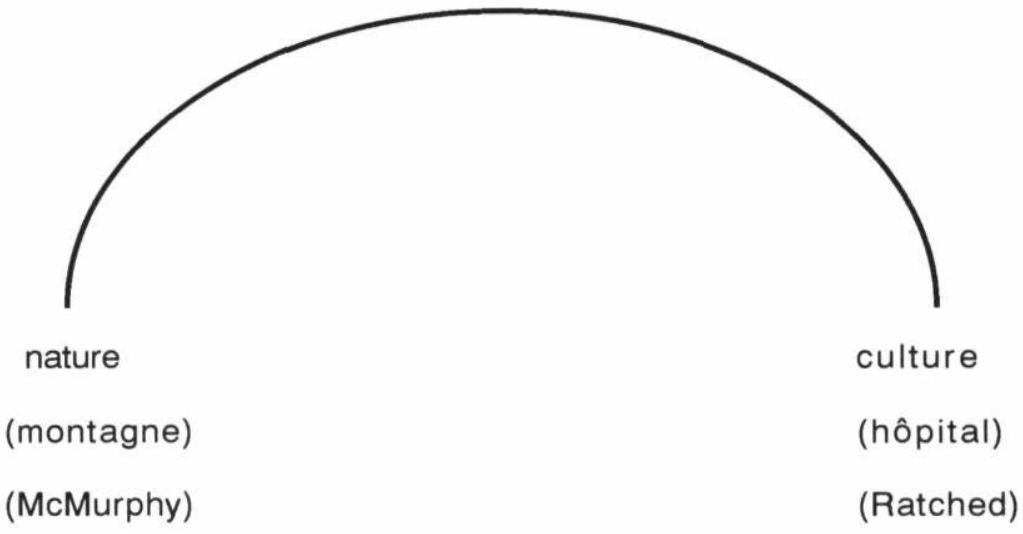

Fig. 3

Schéma initial de l'univers du film.

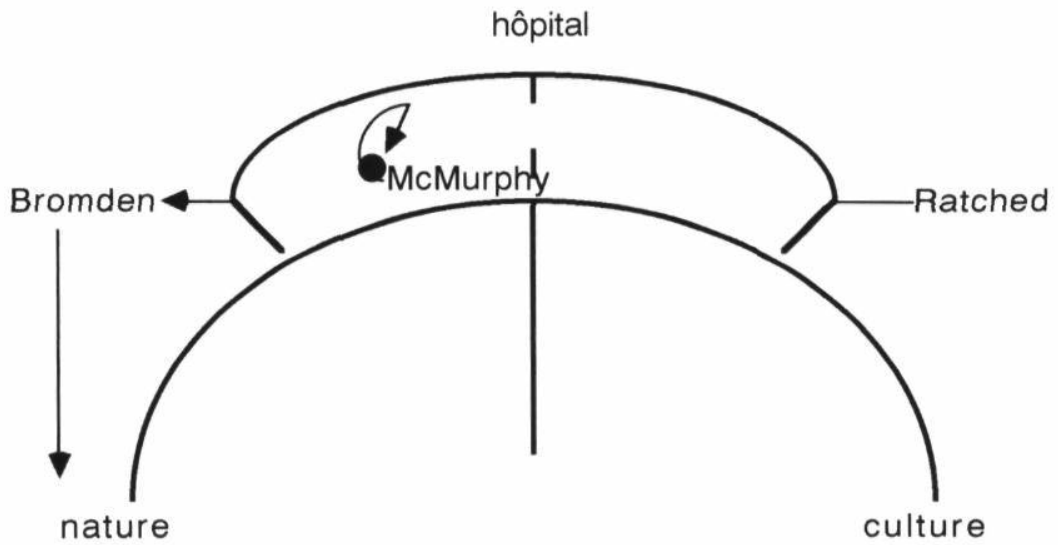

Fig.4 den.

Déplacement définitif du héros McMurphy et de I'Indien Brom- 


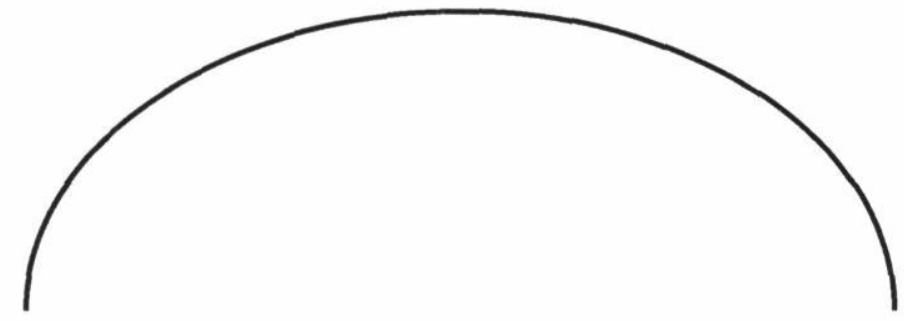

nature

culture

(montagne)

(hôpital)

(Bromden)

(Ratched)

Fig. 5

Schéma final de l'univers du film.

La figure 3 montre l'état des choses à l'arrivée de McMurphy. Il s'agit d'un univers binaire, sans zone frontalière. On retrouve d'un côté la nature, de l'autre la culture, telles que représentées par les deux premiers plans. L'arrivée de McMurphy à l'hôpital redéploie un univers à trois termes. C'est à ce moment qu'on fait connaissance avec le chef Bromden et les autres membres de la communauté hospitalière. Dans cet univers, l'oscillation finale de McMurphy est représentée par la figure 4: elle est analogue à celle du western professionnel, c'est-à-dire que le héros occupe le côté nature de la zone frontalière, suivant son indianisation. Sa mort sacrificielle permettra de transporter son indianité sur Bromden, qui retrouve sa vraie nature. La frontière éphémère est par conséquent détruite et Bromden peut rejoindre la nature, ce qui reproduit l'opposition de départ, comme le montre la figure 5 . Ce jeu de positionnement du héros implique une valorisation positive du plan de la nature et de ses habitants. Conformément à ce modèle, l'Indien sera présenté de façon positive et sa valorisation suit une fois de plus l'axe oppositionnel qui régit les déplacements du héros.

Cette lecture s'oppose à l'interprétation de Bataille et Silet, pour qui l'indianité de Bromden est plus ou moins accidentelle, et résorbe la contradiction notée plus haut. En effet, si le film cherche à mettre en valeur l'Indien, aux dépens d'une culture déshumanisante qui lobotomise les marginaux qui ne veulent pas se joindre à elle, l'image de l'Indien reste victime de cette figure de l'américanité qu'on peut constituer à partir des stéréotypes qu'on 
retrouve dans les westerns. Il ne s'agit pas, bien sûr, d'affirmer que le film de Forman est un western: nous l'avons vu, il n'en est pas un. L'utilisation du modèle de l'univers du western et du réseau normatif qu'on peut en abstraire permet toutefois de remarquer des liens structuraux indéniables quant à la représentation de l'Indien. Celui-ci est toujours lié à la nature, un espace qui produit des marginaux qui ne peuvent être que de deux types: soit des êtres sages, nobles et bons comme Bromden; soit des êtres méchants, bêtes et sales comme McMurphy. C'est de plus ce dernier type d'Indien qui offre ici la possibilité de ressusciter une nature aliénée par la civilisation et par la culture dominante. L'éloge de la nature est ici bien romantique et Bromden qui occupait d'abord la place stéréotypée de l'Indien dans la culture - c'est-à-dire une nature somme toute morte - occupe à la fin du film la place de l'Indien dans une nature qui se meurt. Bromden, ce nouveau «dernier des Mohicans», n'est pas une menace pour la civilisation mais une victime de celle-ci. Les enjeux de l'opposition nature/culture sont réglés depuis belle lurette - au moins depuis le western professionnel. Tant qu'il sera constitué à partir du même réseau normatif, l'Indien demeurera le même, et sa représentation cinématographique inchangée.

University of Alberta

\section{NOTES}

1 Voir Roland Barthes, Mythologies (Paris: Seuil, 1957) et «Rhétorique de l'image», Communications 4 (1964).

2 Philippe Hamon, «Pour un statut sémiologique du personnage», Littérature 6 (1972).

3 Voir Gilles Thérien, Sémiologies (Montréal, Cahiers du département d'études littéraires, UQAM, 1985).

4 Voir Leslie Fiedler, The Return of the Vanishing American (London: Jonathan Cape, 1962).

5 Je résume sommairement l'argument narratif du film de Forman: Randall P. McMurphy est un prisonnier mis sous observation dans un institut psychiatrique. À peine arrivé, il chambarde complètement la vie ordonnée des patients, et en particulier celle du «chef» Bromden. Ce faisant, McMurphy s'attire les foudres de Miss Ratched, l'infirmière en charge. Après une tentative d'évasion ratée, une lobotomie est pratiquée sur McMurphy. L'Indien Bromden, compagnon de McMurphy, s'évade à la fin du film.

6 Voir Martin Lefebvre, «La représentation de l'Indien dans le cinéma américain", Recherches amérindiennes au Québec 17.3 (1987).

7 John Cawelti, The Six Gun Mystique, 2e edition (Bowling Green: Bowling Green State University Popular Press, 1984). 
8 Thomas Schatz, Hollywood Genres: Formulas, Filmmaking and the Studio System (New York: Random House, 1981).

9 Will Wright, Six Guns and Society. A Structural Study of the Western (Berkeley et Los Angeles: University of California Press, 1975).

$10 \mathrm{Jim}$ Kitses, Horizon West (Bloomington: Indiana University Press).

11 Voir Martin Lefebvre, op. cit.

12 Cette référence à la fameuse Nef des fous qui représente leur ségrégation depuis le $X^{e}$ siècle n'est pas aussi gratuite qu'elle puisse paraître. Aussi la retrouve-t-on très précisément dans le film de Forman lorsque McMurphy, lors d'une escapade rocambolesque, détourne un autobus et emmène huit patients à la pêche sur un bateau de plaisance.

13 Sur l'importance de Blake dans l'histoire iconographique de la folie, voir Sander L. Gilman, Seeing the Insane (Toronto: John Wiley, 1982) et Images of Illness From Madness to Aids (Ithaca: Cornell University Press, 1988).

14 Voir "Madness" in Charles Bell, Essays on the Anatomy of Expression in Painting (London: Longman, 1806).

15 C'est moi qui souligne. Voir à ce sujet Roland Jaccard, La Folie (Paris, P.U.F., 1979).

16 Une autre façon de lier indianité et folie passe par la sexualité: dans le bureau du directeur de l'institut psychiatrique, McMurphy mime une masturbation. Cette pratique, nous le savons tous, a longtemps été considérée comme une des origines de la folie. Voir Gilman, op. cit., 1988.

\section{OUVRAGES CITÉS}

Bataille, Gretchen M. et Charles P. Silet. The Pretend Indians. Images of Native Americans in the Movies. Ames: Iowa State University Press, 1981.

Jaccard, Roland. La Folie. Paris: P.U.F., 1979.

Leutrat, Jean-Louis. Le Western. Paris: Armand Colin, 1973. 